\title{
Comparison of Two Methods to Identify Major Personality Factors
}

\author{
Andren Lom Comey

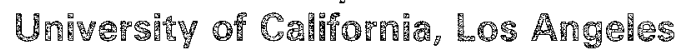

Both Howarth and Comrey have developed taxonomies of personality traits and inventories to measure them. The Howarth Personality Questionnaire and Additional Personality Factor inventories include $20 \mathrm{fac}-$ tors, whereas the Comrey Personality Scales (CPS) taxonomy includes eight factors. Howarth identified his factors through factor analysis of iterns, whereas Comrey identified his primary level factors through factor analysis of conceptually distinct clusters of homogeneous items, called Factored Homogeneous Item Dimensions (FHIDs), while avoiding the inclusion of highly redundant variables in the same analysis. Data for all three inventories were collected from the same subjects and factor analyzed. The Howarth factor scales were narrower in content and more highly overlapping than the CPS factor scales. Most of the Howarth factor scales were good marker variables for the CPS primary factors. Five CPS factors had major loadings for more than one of the Howarth factor scalles. The CPS Emotional Stability vs. Neuroticism (\$) primary level factor was split into several lower level factors in the Howarth system. Factor analysis of items is recommended to identify FHIDs. Factor analysis of FHDs, in which no two FHIDs are merely alternate forms of the same conceptual variable, is recommended to identify the major primary factors of personality.

Where factor analysis has been employed as the means of identifying important personality dimensions, the most commonly used technique has been

APPLIED PSYCHOLOGICAL MEASUREMENT

Vol. 8, No. 4, Fall 1984, pp. 397-408

(C) Copyright 1984 Applied Psychological Measurement Inc. 0146-6216/84/040397-12\$1.85 to factor analyze pools of inventory items. Very early in his attempts to develop a taxonomy of personality traits, Comrey discovered several problems with this approach. As a consequence, he developed a different strategy to avoid these difficulties, and after 10 years of programmatic research, published a new taxonomy of personality traits and an inventory to measure them (Comrey, 1970a, 1970b). The purpose of the present paper is to describe and contrast these two approaches to finding the most important personality dimensions. Data obtained on the same subjects from personality inventories developed by these two approaches were analyzed together to provide an empirical basis for this comparison.

The personality taxonomy developed by Howarth provides an example of using factor analysis of items to locate the most important factors of personality. Through extensive factor analytic studies of large numbers of personality questionnaire items, Howarth has identified 20 major trait factors of personality (Howarth, 1980c; Howarth \& Browne, 1971, 1977). The 10 most important and reliable of these, measured by 10 scales of 12 true-false items each, make up the Howarth Personality Questionnaire (HPQ; Howarth, 1980b). The second 10 factors, in terms of importance and reliability, also measured by 10 scales of 12 true-false items each, make up the Howarth Additional Personality Factor Inventory (APF; Howarth, 1980a).

Starting with an initial study defining the role of 
the Factored Homogeneous Item Dimension (FHD) in personality research (Comrey, 1967), Comrey began a series of investigations designed to determine what are the most important dimensions of personality that can be measured by inventories. This work culminated in the identification of eight major personality constructs and the development of an inventory to measure them-the Comrey Personality Scales (CPS; Comrey, 1970a). The numerous empirical investigations by Comrey and his colleagues describing this endeavor are not reviewed here since they are summarized and referenced in the CPS manual (Comrey, 1970b).

The replicability of these eight personality factors had been well established by empirical studies at the time the CPS was published. Several subsequent studies by Comrey and other investigators provided additional confirming evidence demonstrating the robustness of this eight-factor taxonomy in diverse cultural settings in the United States and abroad (Forbes, Dexter, \& Comrey, 1974; Montag \& Comrey, 1982; Rodrigues \& Comrey, 1974; Vandenberg \& Price, 1978; Zamudio, Padilla, \& Comrey, 1983). Studies showing the clinical utility of these constructs and a discussion of their interesting connection to psychoanalytic theory are presented in Comrey (1980). A recent study showed that these factor traits discriminate well between normals and psychiatric outpatients (Comrey \& Schiebel, 1983).

The CPS taxonomy was developed using factor analytic methods. The fundamental goal of the original research was to find the most important unitary factors of personality, not just an arbitrary set of personality descriptors that would have no special merit beyond that of any other personality taxonomy. This goal was achieved by the development of a hierarchical factor model and of a unique method for locating factor constructs at the proper level in the hierarchy.

Early research showed that a personality factor to measure virtually any defined construct could be developed through skillful item writing and persistent item revision in programmatic research. The factors of this kind were called FHIDs. For several personality items to qualify as a FHDD, two con- ditions had to be met: (1) they were all developed to measure the same conceptually defined construct, and (2) in a factor analysis of items, they demonstrated an acceptable level of homogeneity by defining a separate factor from other items included in the analysis but designed to measure different constructs. Such FHIDs are potentially almost as numerous as there are descriptive personality terms in the language.

FHIDs and other factors like them are at the lowest level in the hierarchy of factors. The distinguishing feature of these factors is that the variables defining them all represent alternate forms measures of the same construct. A factor defined by two items, "I feel depressed" and "I often feel blue" would be an example. A factor defined by "diastolic blood pressure" and "systolic blood pressure" would be another example of this type of factor but outside the domain of personality. Unfortunately, many, if not most of the personality "factors" uncovered by past factor analytic research fall at this lowest level in the hierarchy of factors or are mixtures of factors at this level and higher levels. These mixed, or "hybrid," factors have at least two variables with high loadings that are alternate forms of each other, but they also have at least one other variable with a major loading for a variable with correlated but not conceptually identical content.

The factors in the CPS taxonomy fall at the next higher level in the hierarchy of factors, or the "primary" level. These factors occur because the lowest level "specific" factors are correlated. A primary level factor is represented by defining variables that are correlated yet are conceptually distinct from one another. The defining variables are not merely alternate forms of each other. These factors are, as a consequence, broader in their scope. They are also distinctly limited in number, whereas there is virtually no limit on the number of possible specific level factors. A specific level factor, or FHD, may be a good defining variable for a major primary level factor, but it cannot be identical with the primary level factor since the latter must be defined by several conceptually distinct but correlated variables. The specific level FHID Depression, for 
example, is a good defining variable for the important primary level factor Emotional Stability vs. Neuroticism ( $\$$ ) in the CPS taxonomy.

So far, only eight primary level factors of personality have been located and replicated. Undoubtedly others can be located. Over a series of programmatic factor analytic studies, five defining FHIDs were developed for each of the eight CPS factors. Some of these have loadings that are lower than optimum on the factors they are supposed to define or are higher than they should be on factors they are not supposed to define. Undoubtedly other FHID can be created that would be superior to some of those now being used in the CPS.

Legitimate additions to this eight-factor taxonony could be made by first developing several FHIDs that define the proposed related subconstructs in any new primary level factor. Then, it should be shown that these new variables define a separate factor when included in an analysis with the 40 FHIDs defining and producing the eight CPS factors. These new variables also should not have major loadings on any of the previously developed CPS factors that emerge in the same analysis.

An important point to emphasize is that primary level factors emerge from an analysis when steps are taken to prevent the emergence of specific level factors. This is accomplished by making certain that no two variables in the analysis to locate primary level factors represent mere alternate forms measures of the same conceptual variable. Otherwise, a specific or perhaps a hybrid level factor will emerge, defined totally or in part by these two or more alternate forms variables. Admittedly, a question sometimes arises whether two variables are sufficiently similar to be classified as altemate forms measures. Failure to deal adequately with this problem can lead to some blurring of the distinction between specific and primary level factors.

Other attempts at developing taxonomies of personality traits using factor analytic methods have not employed this kind of procedure to insure that the factors identified will be at the primary level. Consequently, other taxonomic research investigations have often identified factors that are at different levels-some specifics, some primaries, and often mixtures of the two levels. Primary level factors themselves are often correlated and hence can give rise to the identification of factors at a still higher, or "type," level. It is contended that the primary level factors are ordinarily the most useful kinds of factors for theory building and personality assessment.

This article's thesis is that the best way to identify the most important personality dimensions is first to locate good FHIDs (i.e., reliable, internally consistent, balanced for response sets, etc.), and then factor analyze these FHIDs to locate the true factors at the primary level. In this process, no two FHIDs can be included in the analysis that are alternate forms measures of the same concept. This procedure was used to develop the CPS taxonomy.

The most popular method of identifying personality factor traits has been to factor analyze pools of individual items, usually of the two-choice variety. Correlations among irems, particularly twochoice items, are rather unstable and subject to distortions, providing a poor basis for locating stable factor structures. The factors that emerge in such analyses are also likely to be specific or hybrid factors, defined totally or in part by items that are mere altemate forms of the same concept. This is due to the fact that item pools typically contain several subsets, two or more items each, which could be used to form FHIDs, that is, they are altemate forms items. The presence of these item variables in the analysis will force the emergence of specific and/or hybrid level factors in the factor analysis of items. There is no mechanism in such analyses to force the factors to be only at the primary level. All items that are alternate forms of each other could be eliminated from the pool, but this has not been done in practice. Artificially limiting the number of factors extracted also can force the elimination of specific level factors but allows no control over exactly what level the resulting factors do represent. Usually such factors wind up as complex composites of specific and primary level factors.

Specifically, it is the purpose of this paper to show that when a taxomomy of personality traits is developed by factor analyzing items from item pools, 
instead of analyzing FHDs with systematic constraints on the variables included to eliminate specific level factors, certain consequences are likely to occur: (1) some of the factors are likely to be at the specific level; (2) some of the factors are apt to be hybrid factors, that is, partly at the specific level and partly at a higher level; (3) some of the separate factors obtained may have major loadings on the same CPS primary level factor; (4) some major factors at the primary level found by the systematic procedures used in developing the CPS taxonomy may not be identified at all or may be identified only poorly; and (5) the CPS factors that are identified are apt to be represented by fewer defining subvariables, that is, two or three instead of five or more.

\section{Method}

\section{Sabjects}

The Howarth HPQ and APF inventories and the CPS were administered to 52 male and 72 female volunteer subjects, who participated in the research under the motivation of receiving feedback on their test resuits. About two-thirds of the subjects were University of California, Los Angeles students and staff. The rest were friends, relatives, and acquaintances of the student volunteers. Males and females were combined since the samples were small. Each subject received a summary of his or her test results for participating. The total sample mean age was 25.0 with a standard deviation of 13.1.

\section{Variates}

Total scores were computed for the 40 four-item FHIDs that define the eight factors in the CPS taxonomy, five FHIDs per factor. Total scores were also computed for the CPS Validity (V) scale and for the Response Bias (R) scale, a measure of social desirability. The 40 FHID scores, $V, R$, Age, and Sex made up the 44 variables factor analyzed in the original normative group study (Comrey, 1970b) that demonstrated the factor structure underlying the CPS.

Total scores were also computed for the $10 \mathrm{Ho}$ warth HPQ factors and for the 10 Howarth $A P F$ factors. This provided a total of 64 variables to be factor analyzed. The names of these variables and a sample item for each are given in Table 1. All CPS items use a seven-choice scale, either a frequency scale ( $X$-items) or a degree of conviction scale ( $Y$-items). The Howarth items use a true-false scale. For the Howarth scales, only a general description of item content is given rather than actual item examples, for copyright reasons.

Variables 1 through 5 are the FHIDs expected to define the CPS personality factor Trust vs. Defensiveness (T). Variables 6 through 10 are the FHIDs expected to define the CPS Orderliness vs. Lack of Compulsion (O) factor. Variables 11 through 15 are the FHIDs expected to define the CPS Social Conformity vs. Rebelliousness (C) factor. Variables 16 through 20 are the FHIDs expected to define the CPS Activity vs. Lack of Energy (A) factor. Variables 21 through 25 are the FHDDs expected to define the CPS Emotional Stability vs. Neuroticism (S) factor. Variables 26 through 30 are the FHIDs expected to define the CPS Extroversion vs. Introversion $(\mathbb{E}$ ) factor. Variables 31 through 35 are the FHIDs expected to define the CPS Masculinity vs. Femininity (M) factor. Variables 36 through 40 are the FHIDs expected to define the CPS Empathy vs. Egocentrism (P) factor.

\section{Fartor Andysis of 64 Variables}

Scores on the 64 variables were intercorrelated using product-moment correlations and factor analyzed by the minimum residual method (Comrey, 1973), a method that requires no initial communality estimates. The derived communalities from this initial factor extraction were used in a second factor extraction by the principal factor mechod, extracting 12 factors with eigenvalues of $7.41,6.77$, $5.16,3.33,2.30,1.95,1.69,1.55,1.41,1.08$ .99 , and .95 , respectively. Even though communalities were used in the diagonals instead of unities, there were still 10 factors with eigenvalues greater than 1.0 , strongly suggesting the presence of at least 10 factors.

These 12 principal factors were rotated by the 
Table 1

Variables Analyzed and Sample Items

\begin{tabular}{|c|c|c|c|}
\hline Variable & $\begin{array}{l}\text { Item } \\
\text { Number }\end{array}$ & $\begin{array}{l}\text { Scale } \\
\text { Type }\end{array}$ & $\begin{array}{l}\text { Sample Item } \\
\text { or Description }\end{array}$ \\
\hline 1 Lack of Cynicism & 1 & $X$ & The average person is honest. \\
\hline 2 Lack of Defensiveness & 19 & $X$ & $\begin{array}{l}\text { You can get what is coming to you without } \\
\text { having to be aggressive or competitive. }\end{array}$ \\
\hline 3 Belief in Human Worth & 37 & $Y$ & Most people are valuable human beings. \\
\hline 4 Trust in Human Nature & 10 & $X$ & $\begin{array}{l}\text { Other people are selfishly concerned about } \\
\text { themselves in what they do. }\end{array}$ \\
\hline 5 Lack of Paranoia & 28 & $X$ & $\begin{array}{l}\text { Some people will deliberately say or do } \\
\text { things to hurt you. }\end{array}$ \\
\hline 6 Neatness & 2 & $Y$ & $\begin{array}{l}\mathbb{I} \text { could live in a pig pen without letting it } \\
\text { bother me. }\end{array}$ \\
\hline 7 Routine & 20 & $Y$ & $\begin{array}{l}\text { Living according to a schedule is something } \\
\text { I like to avoid. }\end{array}$ \\
\hline 8 Order & 38 & $X$ & My room is a mess. \\
\hline 9 Cautiousness & 11 & $X$ & I am a cautious person. \\
\hline 10 Meticulousness & 29 & $X$ & $\begin{array}{l}\text { I will go to great lengths to correct mistakes } \\
\text { in my work which other people wouldn't } \\
\text { even notice. }\end{array}$ \\
\hline 11 Law Enforcement & 3 & $Y$ & $\begin{array}{l}\text { This society provides too much protection } \\
\text { for criminals. }\end{array}$ \\
\hline 12 Acceptance of Social Order & 21 & $Y$ & $\begin{array}{l}\text { The laws governing the people of this } \\
\text { country are sound and need only minor } \\
\text { changes, if any. }\end{array}$ \\
\hline 13 Intolerance of Non-Conformity & 39 & $Y$ & $\begin{array}{l}\text { Young people should be more willing than } \\
\text { they are to do what their elders tell them } \\
\text { to do. }\end{array}$ \\
\hline 14 Respect for Law & 12 & $X$ & $\begin{array}{l}\text { If the laws of society are unjust, they should } \\
\text { be disobeyed. }\end{array}$ \\
\hline 15 Need for Approval & 30 & $X$ & $\begin{array}{l}\text { I ignore what my neighbors might think of } \\
\text { me. }\end{array}$ \\
\hline 16 Exercise & 4 & $X$ & $\begin{array}{l}\text { If I think about exercising, I lie down until } \\
\text { the idea goes away. }\end{array}$ \\
\hline 17 Energy & 22 & $X$ & $\begin{array}{l}\text { I seem to lack the drive necessary to get } \\
\text { things done. }\end{array}$ \\
\hline 18 Need to Excel & 40 & $Y$ & $\begin{array}{l}\text { Being a big success in life requires more } \\
\text { effort than I am willing to make. }\end{array}$ \\
\hline 19 Liking for Work & 13 & $X$ & I love to work long hours. \\
\hline 20 Stamina & 31 & $X$ & I can work a long time without feeling tired. \\
\hline 21 Lack of Inferiority Feelings & 6 & $X$ & I feel inferior to the people I know. \\
\hline 22 Lack of Depression & 24 & $X$ & $\begin{array}{l}\text { I feel so down-in-the-dumps that nothing can } \\
\text { cheer me up. }\end{array}$ \\
\hline 23 Lack of Agitation & 42 & $X$ & My nerves seem to be on edge. \\
\hline 24 Lack of Pessimism & 15 & $X$ & I expect things to turn out for the best. \\
\hline 25 Mood Stability & 33 & $X$ & $\begin{array}{l}\text { My mood remains rather constant, neither } \\
\text { going up nor down. }\end{array}$ \\
\hline 26 Lack of Reserve & 7 & $X$ & I am a very talkative person. \\
\hline 27 Lack of Seclusiveness & 25 & $X$ & $\begin{array}{l}\text { At a party ll like to meet as many people as } \mathbb{I} \\
\text { can. }\end{array}$ \\
\hline 28 No Loss for Words & 43 & $X$ & It is easy for me to talk with people. \\
\hline
\end{tabular}

continued on next page

Downloaded from the Digital Conservancy at the University of Minnesota, http://purl.umn.edu/93227. May be reproduced with no cost by students and faculty for academic use. Non-academic reproduction requires payment of royalties through the Copyright Clearance Center, http://www.copyright.com/ 
Table 1 , continued

Variables Analyzed and Sample Irems

\begin{tabular}{|c|c|c|c|c|}
\hline & Variable & $\begin{array}{l}\text { Irem } \\
\text { Number }\end{array}$ & $\begin{array}{l}\text { Scale } \\
\text { Type }\end{array}$ & $\begin{array}{l}\text { Sample Item } \\
\text { or Description }\end{array}$ \\
\hline & Lack of Shyness & 16 & $x$ & $\begin{array}{l}\text { I find it difficult to talk with a person } I \text { have } \\
\text { just met. }\end{array}$ \\
\hline 30 & No Stage Fright & 34 & $Y$ & $\begin{array}{l}\text { It would be hard for me to do anything in } \\
\text { front of an audience. }\end{array}$ \\
\hline 31 & No Fear of Bugs & 8 & $X$ & $\begin{array}{l}\text { Big bugs and other crawling creatures upset } \\
\text { me. }\end{array}$ \\
\hline 32 & No Crying & 26 & $X$ & A sad movie makes me feel like crying. \\
\hline 33 & No Romantic Love & 44 & $X$ & $\begin{array}{l}1 \text { like movies which tell the story of two } \\
\text { people in love. }\end{array}$ \\
\hline 34 & Tolerance of Blood & 17 & Y & $\begin{array}{l}\mathbb{1} \text { could assist in a surgical operation without } \\
\text { fainting if } \mathbb{1} \text { had to. }\end{array}$ \\
\hline 35 & Tolerance of Vulgarity & 35 & $X$ & I can tolerate vulgarity. \\
\hline 36 & Sympathy & 9 & $X$ & I am very kindhearted. \\
\hline 37 & Helpfulness & 27 & $Y$ & $\begin{array}{l}\text { I enjoy helping people even if } \mathbb{I} \text { don't know } \\
\text { them very well. }\end{array}$ \\
\hline 38 & Service & 45 & Y & $\begin{array}{l}\text { I would like to devote my life to the service } \\
\text { of others. }\end{array}$ \\
\hline 39 & Generosity & 18 & $Y$ & $\begin{array}{l}\text { I would hate to make a loan to a poor family } \\
\text { I didn't know very well. }\end{array}$ \\
\hline 40 & Unselfishness & 36 & 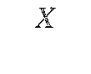 & $\begin{array}{l}\text { I take care of myself before I think about } \\
\text { other people's needs. }\end{array}$ \\
\hline 41 & CPS Validity Scale (V) & 5 & $\mathbb{I}$ & $\begin{array}{l}\text { If I were asked to lift a ten ton weight, I } \\
\text { could do it. }\end{array}$ \\
\hline 42 & CPS Response Bias Score $(\mathbb{R})$ & 41 & $X$ & My morals are above reproach. \\
\hline 43 & Age & - & - & Correlated as a two-digit number. \\
\hline 44 & $\operatorname{Sex}$ & - & - & Male $=1$, Female $=0$ \\
\hline 45 & HPQ Sociability (SY) & - & - & Liking for social contact. \\
\hline 46 & HPQ Anxiety (AE) & - & - & Tendency to be nervous, upset. \\
\hline 47 & HPQ Dominance (AD) & - & - & Tendency to dominate others. \\
\hline 48 & HPQ Conscience (SG) & - & 一 & Tendency to abey social norms. \\
\hline 49 & HPQ Hypochondriasis (HM) & - & - & Concern for health problems. \\
\hline 50 & HPQ Impulsive (IP) & - & - & Failure to plan ahead. \\
\hline & $\begin{array}{l}\text { HPQ Cooperative-Considerateness } \\
\text { (CC) }\end{array}$ & - & - & Concern for others. \\
\hline 52 & HPQ Inferiority (IF) & - & - & Feelings of unworthiness. \\
\hline 53 & HPQ Persistence (PS) & - & - & Ability to persist in an accivity. \\
\hline 54 & HPQ Suspicion vs. Trust (ST) & - & - & Tendency to distrust others. \\
\hline 55 & $\begin{array}{l}\text { APF Fear of Being Socially } \\
\text { Unacceptable (FS) }\end{array}$ & - & - & $\begin{array}{l}\text { Fear of doing the wrong thing in a social } \\
\text { context. }\end{array}$ \\
\hline 56 & APF Hope (HP) & - & - & Optimistic, hard to defeat, resurgent. \\
\hline 57 & APF General Activity (GA) & - & - & Active and Energetic. \\
\hline 58 & APF Anxiety State (AS) & - & - & Present feeling of anxiousness. \\
\hline 59 & APF Existential Realization (ER) & - & - & $\begin{array}{l}\text { Tendency to believe that life has no ultimate } \\
\text { purpose or meaning. }\end{array}$ \\
\hline 60 & $\mathrm{APF}$ lavolvement (IV) & - & - & Liking to help other people. \\
\hline 61 & APF Unusuality (UP) & - & - & Craving for novelty and new experience. \\
\hline 62 & APF Dislikes-Annoyances (DA) & - & - & Tolerance for annoyances of life. \\
\hline 63 & APF External Control $(\mathbb{E C})$ & - & - & $\begin{array}{l}\text { Belief that what happens to you is beyond } \\
\text { your own control. }\end{array}$ \\
\hline 64 & APF Rigidity $(\mathbb{R Y})$ & - & - & $\begin{array}{l}\text { Set in one's ways; unadaptive to new } \\
\text { situations. }\end{array}$ \\
\hline
\end{tabular}

Downloaded from the Digital Conservancy at the University of Minnesota, http://purl.umn.edu/93227. May be reproduced with no cost by students and faculty for academic use. Non-academic reproduction requires payment of royalties through the Copyright Clearance Center, http://www.copyright.com/ 
Tandem Criterion I method of the Tandem Criteria (Comrey, 1967, 1973). This method places as much variance on the early factors as can be justified by the requirement that variables appearing on the same factor must be correlated. This permits discarding small factors that are unable to capture significant amounts of common factor variance from the early extracted principal factors during the rotation process. The sums of squares for the Criterion I factors were, in order of size: $5.88,5.70,5.65,4.01,2.67$, $2.13,1.75,1.68,1.63,1.28,1.12$, and 1.09. Considering loadings of 3 or more, Factor 12 had only a single loading of .34 (for Variable 39); Factor 11 had loadings of .34, .37, and .34 for Variables 7 , 41 , and 34, respectively. Both these factors had small sums of squares and were dropped as insignificant. Thus, analysis of the Criterion I factors and their sums of squares also suggested the presence of 10 factors.

Factor 10 had loadings of .40 and .70 for Variables 33 (Unselfishness) and 43 (Age), respectively. It was retained as a minor factor of limited importance. Factor 8 had loadings of 3 or more on the following variables: 7 (Routine), $-.32 ; 9$ (Cautiousness), $-.56 ; 13$ (Intolerance of NonConformity), .34; 50 (Impulsiveness), .53; and 62 (Dislikes-Amnoyances), -.31 . This is a specificlevel factor generated in this analysis because the items defining Howarth's HPQ Impulsive (IP) factor are similar to those defining the CPS FHID Cautiousness, which is supposed to define the CPS O factor. Factor 8 was retained in this analysis as a separate specific factor, or FHID. A factor of this kind would not appear in a usual analysis of CPS FHDD to locate primary level factors because alternate forms variables are excluded from such analyses, precisely to obviate the emergence of factors such as this one. The presence of this factor in the current analysis, however, probably has reduced the loading for the Cautiousness FHID on the primary level $O$ factor, where it is expected to appear.

The remaining eight Criterion 1 factors all were substantial in size and nascent representatives of primary level CPS factors identified in the past. These eight Criterion I factors were rotated by $\mathrm{Cri}$ terion II of the Tandem Criteria, which provides a solution more closely approximating simple struc- ture. The Tandem Criteria provide an orthogonal solution, even though it has been well established that the underlying CPS factors are oblique. An orthogonal solution is used here primarily for convenience in reporting. The oblique solution would still have the same variables with major loadings on each factor as shown in the original nonm group analysis (Comrey, 1970b), in which both the orthogonal and oblique solutions were given. The correlations among CPS scales and among oblique factors from that analysis are reproduced in Table 2 to give some indication of the actual degree of obliguity present in the CPS eight-factor system. For comparison, the same eight Criterion I factors were also rotated by the normal varimax method (Kaiser, 1958). This solution is not reported here because it was virtually identical with the Tandem Criterion II solution.

Rotation of seven Criterion $\mathbb{I}$ factors by varimax merely collapsed factors $O$ and $C$, the two most highly correlated CPS factors. Rotation of only six factors by varimax collapsed $O$ and $C$ into one factor and $T$ and $\mathbb{P}$ into another. Rotation of five factors collapsed these four factors into two factors and lost the $\mathbb{M}$ factor altogether. These various analyses strongly support the conclusion that this $64 \times 64$ correlation matrix yields eight major factors at the primary level, a major specific level factor, and one minor factor with Age as the only variable with a large loading.

\section{Tractor Analyses of HPO and APR Thems}

In addition to the major factor analysis of the 64 variables, four factor analyses of Howarth questionnaire items were carried out: (1) 60 items in HPQ scales 1 through 5; (2) 60 items in HPQ scales 6 through 10 ; (3) 60 items in APF scales 1 through 5; and (4) 60 items in APF scales 6 through 10 . Age and Sex were added as variables 61 and 62 in each of these analyses. These analyses were designed to determine if the Howarth scale items would define single major item factors or whether two or more item clusters would appear for a given scale. Where more than one item factor appeared for a given Howarth scale, item content was examined for clues as to the reason for the scale's split into more than one item cluster. 
Table 2

Intercorrelations Among Scales and Among oblique Factors

\begin{tabular}{|c|c|c|c|c|c|c|c|c|c|c|}
\hline & V & $R$ & $\mathrm{~T}$ & 0 & $\mathrm{C}$ & $A$ & 5 & $E$ & $\mathrm{M}$ & P \\
\hline $\begin{array}{l}V \\
R\end{array}$ & 12 & & & & & & & & & \\
\hline $\mathrm{T}$ & -08 & 26 & & 04 & 04 & $\mathbb{1 5}$ & 43 & 16 & -14 & 3 \\
\hline 0 & -02 & 34 & -0.1 & & 48 & -03 & 01 & 04 & -27 & 02 \\
\hline C & 07 & 37 & 08 & 47 & & 00 & 03 & -03 & -11 & $=04$ \\
\hline A & 08 & 27 & 10 & 23 & 15 & & 42 & 37 & 12 & 24 \\
\hline$S$ & 01 & 20 & 31 & 04 & 08 & 42 & & 35 & -06 & 19 \\
\hline$E$ & -02 & 11 & 17 & 02 & 01 & 35 & 41 & & -27 & 25 \\
\hline $\mathrm{M}$ & 14 & -24 & -08 & -27 & -30 & 15 & 17 & 04 & & -30 \\
\hline$P$ & -07 & 39 & 32 & 04 & 02 & 29 & 15 & 26 & -22 & \\
\hline
\end{tabular}

Note. Correlations below the main diagonal are between factor scales. Correlations above the main diagonal are for oblique factors.

\section{Resthents}

Factor loadings for the eight major factors in the 64-variable analysis are shown in Table 3 . Only loadings of .3 or more are shown (without decimal points), except where a given CPS FHID was expected to have a major loading on that factor, it is shown regardless of size.

Each of the eight primary level factors obtained in this analysis could be identified as being very similar to one of the eight factors in the taxonomy underlying the CPS. Loadings for the CPS FHDs on these factors in the original normative group analysis are available elsewhere (Comrey, 1970b). Inspection of Table 3 shows that most of the CPS FHDs had a major loading on the factor they were expected to define and not on any other factor. Notable exceptions included the following: (1) a loading of .58 for 3 (Belief in Human Worth) on the Empathy vs. Egocentrism $(\mathbb{P})$ factor; (2) loadings of .45 for 6 (Neatness) and .41 for 8 (Order) on the Social Conformity vs. Rebelliousness (C) factor; (3) a loading of .39 for 12 (Acceptance of the Social Order) on the Trust vs. Defensiveness (T) factor; (4) a loading of -.49 for 35 (Tolerance for Vulgarity) on the Social Conformity vs. Rebelliousness (C) factor; and (5) FHIDs 15 (Need for Approval) and 34 (Tolerance of Blood) failed to have major loadings on any factor. Given the small sample with consequently rather unstable correla- tion coefficients plus the addition of 20 other variables to the analysis that could substantially infuence the placement of the factors, the agreement of this solution for the CPS FHIDs with expectations was on the whole acceptable for most factors.

Although most of the Howarth factor scales showed a major loading on one of the CPS factors, no major factor in this analysis was defined only by Howarth factor scales. This is not surprising since each Howarth scalle was supposed to define a separate factor and this analysis included only total scores for the Howarth factors.

\section{Fator Analysis of HPO and APR ltems}

Space does not permit a detailed presentation of these analyses, so the results are merely summarized. For the $\mathrm{HPQ}$ scales, IP, IF, and ST gave a single major item factor each; scales $\mathrm{SY}, \mathbb{A E}, \mathbb{A D}$, $H M$, and $C C$ each contained two major item factors; scales SG and PS had three item factors each. For the APF scales, HP, AS, ER, IV, and DA gave a single major item factor each; scales FS, GA, $\mathbb{E C}$, and $P Y$ each gave two major item factors. Scalle UP had only two relatively minor item factors. This was the least homogeneous of the Howarth factor scales.

Thus, 8 of the 20 Howarth factors are represented by item collections that generated a single major factor in factor analyses of items, one factor 
Table 3

Rotated Factor Matrix

\begin{tabular}{|c|c|c|c|c|c|c|c|c|c|}
\hline Variable & $\mathrm{T}$ & 0 & $\mathrm{C}$ & A & 5 & E & $M$ & P & $h^{2}$ \\
\hline \multicolumn{10}{|l|}{ Trust vs Defensiveness $(T)$} \\
\hline 1. Lack of Cynicism & 67 & & & & & & & & 60 \\
\hline 2. Lack of Defensiveness & 44 & & & & & & & & 31 \\
\hline 3. Belief in Human Worth & 39 & & & & & & & 58 & 55 \\
\hline 4. Trust in Human Worth & 50 & & & & & & & & 38 \\
\hline 5. Lack of Paranoia & 67 & & & & & & & & 54 \\
\hline \multicolumn{10}{|l|}{ Orderliness vs Lack of Comp. (0) } \\
\hline 6. Neatness & & 42 & 45 & & & & & & 45 \\
\hline 7. Routine & & 53 & & & & & & & 38 \\
\hline 8. order & & 37 & 41 & & & & & & 48 \\
\hline 9. Cautiousness & & 72 & & & & & & & 62 \\
\hline 10. Heticulousness & & 35 & & 32 & & & & & 31 \\
\hline \multicolumn{10}{|l|}{ Social Conformity vs Rebell. (C) } \\
\hline 11. Law Enforcement & & & 50 & & & & & & 35 \\
\hline 12. Acceptance of Social Order & 39 & & 18 & & & & & & 24 \\
\hline 13. Intol. of Non-Conformity & & & 77 & & & & & & 65 \\
\hline 14. Respect for Law & & 35 & 48 & & & & & & 48 \\
\hline 15. Need for Approval & & & 29 & & & & & & 26 \\
\hline \multicolumn{10}{|l|}{ Activity vs Lack of Energy (A) } \\
\hline 16. Exercise & & & & 46 & & & & & 28 \\
\hline 17. Energy & & & & 68 & & 40 & & & 64 \\
\hline 18. Need to Excel & & & & 55 & & & & & 48 \\
\hline 19. Liking for Work & & & & 56 & & & & & 44 \\
\hline 20. Stamina & & & & 69 & & & & & 53 \\
\hline \multicolumn{10}{|l|}{ Emotional Stability vs $N_{0}$ (S) } \\
\hline 21. Lack of Inferiority $\mathrm{F}$. & & & & & 60 & & & & 50 \\
\hline 22. Lack of Depression & 35 & & & & 56 & & & & 48 \\
\hline 23. Lack of Agitation & & & & & 67 & & & & 59 \\
\hline 24. Lack of Pessimism & & & & & 52 & & & & 45 \\
\hline 25. Mood Stability & & & & & 65 & & & & 50 \\
\hline \multicolumn{10}{|l|}{ Extraversion vs Introver. (E) } \\
\hline 26. Lack of Reserve & & & & & & 83 & & & 72 \\
\hline 27. Lack of Seclusiveness & & & & & & 48 & & & 47 \\
\hline 28. No Loss for Words & & & & & & 81 & & & 76 \\
\hline 29. Shyness & & & & & & 72 & & & 62 \\
\hline 30. No Stage Fright & & & & & & 58 & 35 & & 55 \\
\hline \multicolumn{10}{|l|}{ Masculinity vs Femininity (M) } \\
\hline 31. No Fear of Bugs & & & & & & & 49 & & 32 \\
\hline 32. No Crying & & & & & & & 70 & & 54 \\
\hline 33. No Romantic Love & & & & & & & 39 & & 28 \\
\hline 34. Tolerance of Blood & & & & & & & 26 & & 24 \\
\hline 35. Tolerance of Vulgarity & & & -49 & & & & 50 & & 52 \\
\hline \multicolumn{10}{|l|}{ Empathy vs Egocentrism (P) } \\
\hline 36. Sympathy & & & & & & & -34 & 60 & 53 \\
\hline 37. Helpfulness & & & & & & & & 66 & 65 \\
\hline 38. Service & & & & & & & & 67 & 50 \\
\hline 39. Generosity & & & & & & & & 43 & 29 \\
\hline 40. Unselfishness & & & & & & & & 53 & 48 \\
\hline
\end{tabular}

- continued on the next page -

Downloaded from the Digital Conservancy at the University of Minnesota, http://purl.umn.edu/93227. May be reproduced with no cost by students and faculty for academic use. Non-academic reproduction requires payment of royalties through the Copyright Clearance Center, http://www.copyright.com/ 
Table 3 (Continued)

Rotated Factor Matrix

\begin{tabular}{|c|c|c|c|c|c|c|c|c|c|}
\hline Variable & $\mathrm{T}$ & 0 & $\mathrm{C}$ & A & $S$ & $E$ & M & $\mathrm{p}$ & $h^{2}$ \\
\hline \multicolumn{10}{|l|}{ Miscellaneous Variables: } \\
\hline 41. CPS Validity Scale (V) & & & & & & & & & 12 \\
\hline 42. CPS Response Bias Scale (R) & & & & & & & & 35 & 33 \\
\hline 43. Age & & & & & & & & & 19 \\
\hline 44. $\operatorname{Sex}(M=1, F=0)$ & & & & & & & 76 & & 59 \\
\hline \multicolumn{10}{|l|}{ HPQ Factor Scales: } \\
\hline 45. Sociability (SY) & & & & & & 67 & & & 58 \\
\hline 46. Anxiety (AF) & -32 & 34 & & & -67 & & & & 74 \\
\hline 47. Dominance (AD) & & & & & & 38 & 44 & & 45 \\
\hline 48. Conscience (SG) & & & 70 & & & & & & 65 \\
\hline 49. Hypochondriasis (HM) & & & & & -47 & & & & 40 \\
\hline 50. Impulsive (IP) & & -62 & & & & & & & 52 \\
\hline 51. Cooperative-Consid. (CC) & & & & & & & & 58 & 47 \\
\hline 52. Inferionity (IF) & & & & -32 & -56 & & -31 & & 64 \\
\hline 53. Persistence (PS) & & & & 72 & & & & & 56 \\
\hline 54. Suspicion vs Trust (ST) & -76 & & & & & & & & 74 \\
\hline \multicolumn{10}{|l|}{ APF Factor Scales: } \\
\hline 55. Fear Social Unacc. (FS) & & & & & & & & & 22 \\
\hline 56. Hope & & & & 37 & & & & & 31 \\
\hline 57. General Activity & & & & 56 & & 40 & & & 57 \\
\hline 58. Anxiety State & & & & & -48 & & & & 38 \\
\hline 59. Existential Rea1. (ER) & -32 & & & & & & & & 26 \\
\hline 60. Involvement (IV) & & & & & & 30 & & 43 & 42 \\
\hline 61. Unusuality (UP) & -48 & & & & & & 36 & & 43 \\
\hline 62. Dislikes-Annoy. (DA) & & 45 & & & & & & & 32 \\
\hline 63. Externa1 Control (EC) & & & & & & & & & 16 \\
\hline 64. Rigidity (RY) & & 51 & & & & & & & 40 \\
\hline
\end{tabular}

per scale. These item factors are close to being like FHIDs in the CPS system, though these item groups are somewhat less homogeneous in most cases than the CPS FHIDs. Nine of the 20 Howarth factors are represented by item collections that generated two major factors in factor analyses of items. Since these factors contain two distinct item subgroups each, they are broader in content than FHIDs but narrower in content than the CPS primary level factors that contain five distinct item subgroups each. These factors are more like hybrid factors than primary level factors since their placement is dictated by the specific level variance generated within the two FHDD-like item clusters. Two of the 20 Howarth factors are represented by item groups that generated three distinct item subgroups, so these factors are broader still than the other Ho- warth factors. No Howarth factor generated more than three major item factors in these factor analyses of items.

\section{Loadings of Howarth Scales on CPS Factors}

Major loadings of the Howarth factor scales on the CPS factors can be summarized as follows:

Trust vs. Defensiveness (T): Suspicion vs. Trust (ST), - .76; Unusuality (UP), -.50 .

Orderliness vs. Lack of Compulsion (O): Impulsive (IP), - .60; Dislikes-Annoyances (DA), .41; Rigidity (RY), .50.

Social Conformity vs. Rebelliousness (C): Conscience (SG), .67.

Activity vs. Lack of Energy (A): Persistence (PS), 
.70; Hope (HP), .36; General Activity (GA), .55 .

Emotional Stability vs. Neuroticism (S): Anxiety (AE), - .67; Hypochondriasis (HM), - .50; Inferiority (IF), -.60 ; Anxiety State (AS), -.43 . Extroversion vs. Introversion (E): Sociability (SY), .67.

Masculinity vs. Femininity (M): Dominance (AD), .43 .

Empathy vs. Egocentrism (P): Cooperative-Considerateness (CC), .57; Involvement (IV), .48.

Thus, CPS factors $T, O, A, S$, and $P$ are heavily loaded by two or more Howarth factor scales each; CPS factors $C$ and $E$ are strongly represented by one Howarth factor scale each; and the CPS M factor is represented to a modest extent by one Howarth factor scale. Three Howarth factor scales, FS, ER, and EC, had no loading of .3 or more on any of the CPS factors.

\section{Discunsion}

The sample was small in this study, mainly because it is not easy to induce volunteer subjects to take three full-length personality inventories. The fact that the previously well-established eight-factor structure for the CPS FHIDs was recovered in this analysis with reasonably good accuracy, however, suggests that the large loadings for the Howarth inventory variables on the CPS factors would probably replicate fairly well in a larger sample of the same kind. Whatever changes in these loadings that might occur in a larger sample would be very unlikely to affect the major conclusions of this paper.

Although the factors identified by Howarth are substantially related to seven of eight factors in the CPS taxonomy, some major differences in the two factor systems are apparent. First, the Howarth factors are narrower in content, containing only one or two major item factors in most cases, whereas the CPS factors each contain five conceptually distinct but correlated item factors (the FHIDs). Secondly, the Howarth factor scales are more highly correlated than the CPS factors since five of the CPS factors have major loadings for two or more
Howarth factor scales each. Finally, three of the Howarth factor scales have no loading on any CPS factor, and the CPS M factor and the Howarth $\mathrm{AD}$ factor match each other to only a limited degree.

These differences between the Howarth and Comrey systems of factors can be attributed in part to the fact that Howarth analyzes items to find the major factors, whereas Comrey analyzes FHIDs for this purpose, controlling the pool of variables analyzed to eliminate alternate forms variables. As predicted, the Howarth factors in most cases represented either FHID-type specific level factors or hybrid factors with considerable specific level variance. By factoring items, Howarth (Howarth, 1980a; Howarth \& Browne, 1971, 1977) obtained separate factors for Anxiety (AE), Hypochondriasis (HM), and Inferiority (IF), but when these factor scales were factor analyzed together with the CPS FHIDs, they all had major loadings on the CPS Emotional Stability vs. Neuroticism (\$) factor. This major primary level CPS factor has been split into several separate specific level factors in the Howarth system. This occurs because items of very similar content have considerably higher correlations with each other than they do with items from other item groups that measure conceptually different constructs. Even if these separate item groups correlate sufficiently to produce a higher level factor in an analysis of FHIDs, they can be split into separate factors in a factor analysis of items.

Factoring items can also produce item factors that may not measure any major primary level factor of general interest. The fact that several similar items can be written to measure some construct, leading to the production of an item factor, does not in itself insure that any important construct has been isolated. Three of the Howarth factor scales had no loading of .3 or more on any CPS factor. The items for one of these, Existential Realization $(\mathbb{E R})$, produced only one major factor loaded by most of the items. These three Howarth factor scales may prove to be good marker variables for important primary level factors not found in the CPS system to date, but the identification of an item factor per se does not establish that it is a good marker variable for any important personality factor. 
The most fruitful use of factoring items is to identify variables that may be good marker variables for important primary level personality factors. Factoring items should not be used to identify these major factors themselves. Most of the Howarth scales are in fact shown in this study to be good marker variables for the broader CPS factors. Another advantage of factoring FHIDs, rather than items, is that such variables are composed of several items each. This permits these variables to achieve greater reliability and better distributions than single items, particularly true-false items. Correlations among FHIDs, therefore, are more stable and less subject to distortions than those among items. This leads to better results in the factor analyses of FHDS than with items. Therefore, it is recommended that the search for major personality factors should proceed with factor analyses of FHDs, eliminating alternate forms FHDs from the same analysis, and that factor analysis of items should be reserved for identifying FHIDs that will be good marker variables for the major personality factors.

\section{Preferences}

Comrey, A. L. (1967). Tandem criteria for analytic rotation in factor analysis. Psychometrika, 32, 143-154.

Comrey, A. L. (1970a). Comrey personality scales. San Diego: Educational and Industrial Testing Service.

Comrey, A. L. (1970b). Manual for the Comrey personality scales. San Diego: Educational and Industrial Testing Service.

Comrey, A. L. (1973). A first course in factor analysis. New York: Academic Press.

Comrey, A. L. (1980). Handbook of interpretations for the Comrey Personality Scales. San Diego: EdITs Publishers.

Comrey, A. L., \& Schiebel, D. (1983). Personality test correlates of psychiatric outpatient status. Journal of Consulting and Clinical Psychology, 51, 757-762.

Forbes, A. R., Dexter, W. R., \& Comrey, A. L. (1974). A cross-cultural comparison of certain personality factors. Multivariate Behavioral Research, 9, 383-394.
Howarth, E. (1980a). Additional personality factors inventory. Edmonton, Canada: University of Alberta.

Howarth, $\mathbb{E}$. (1980b). Howarth personality questionnaire. Edmonton, Canada: University of Alberta.

Howarth, E. (1980c). Scale descriptions, norm tables and bibliography for the Howarth Personality Questionnaire (HPQ), Additional Personality Factor Inventory (APF), and Howarth Mood Adjective Checklist ( $H M A C L$ ). Edmonton, Canada: University of Alberta.

Howarth, E., \& Rrowne, J. A. (1971). Investigation of personality factors in a Canadian context. I. Marker structure in personality questionnaire items. Canadian Joumal of Behavioral Science, 3, 161-173.

Howarth, $\mathbb{E}$., \& Browne, J. A. (1977). A comprehensive factor analysis of personality questionnaire items. Multivariate Behavioral Research, 12, 399-427.

Kaiser, H. F. (1958). The Varimax criterion for analytic rotation in factor analysis. Psychometrika, 23, $187-$ 200.

Montag, I., \& Comrey, A. L. (1982). Personality construct similarity in Israel and the United States. Applied Psychological Measurement, 6, 61-67.

Rodrigues, A., \& Comrey, A. L. (1974). Personality structure in Brazil and the United States. The Joumal of Social Psychology, 92, 19-26.

Vandenberg, S. G., \& Price, R. A. (1978). Replication of the factor structure of the Comrey Personality Scales. Psychological Reports, 42, 343-352.

Zamudio, A., Padilla, A. M., \& Comrey, A. L. (1983). Personality structure of Mexican-Americans using the Comrey personality scales. Journal of Personality Assessment, 47, 100-106.

\section{Acknowledgrents}

The author is indebted to Ellen Fink, David Florence, Augie Johnson, and Andrew Lavick for assistance in data collection and handling. Peter M. Bentler kindly offered suggestions for improving the manuscript. Deficiencies that remain are the sole responsibility of the author.

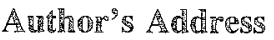

Send requests for reprints or further information to Andrew L. Comrey, Department of Psychology, University of Califomia, Los Angeles CA 90024, U.S.A. 